\title{
Unsettling Video
}

Co-producing a Montage Film with an Infant

\author{
Deborah Silvis \\ Utah State University, Logan, USA \\ deborah.silvis@usu.edu
}

\begin{abstract}
This article is a reflection on the process and epistemological affordances of coproducing video with an infant. Through the lens of montage filmmaking, a number of novel perspectives on learning came into view. For one, the infant's ways of knowing through the body were foregrounded, and speech and language played a backstage role. This then placed attention on how bodies carry intensities and vitality not adequately represented through text (Manning \& Massumi, 2014; Stern, 2010). In addition, this approach supported going beyond conventional uses of video as data; data tend to be taken as "given," or alternatively, as "created" but then given over to the analytic gaze. As another approach to video recordings of learning, video montage reanimated aesthetics and movement instead of discourse and meaning as the leading foci of inquiry. The result unsettled received notions of both video production and knowledge production.
\end{abstract}

\section{Keywords}

video data - montage film - infants - situated learning - aesthetics - digital ethnography 


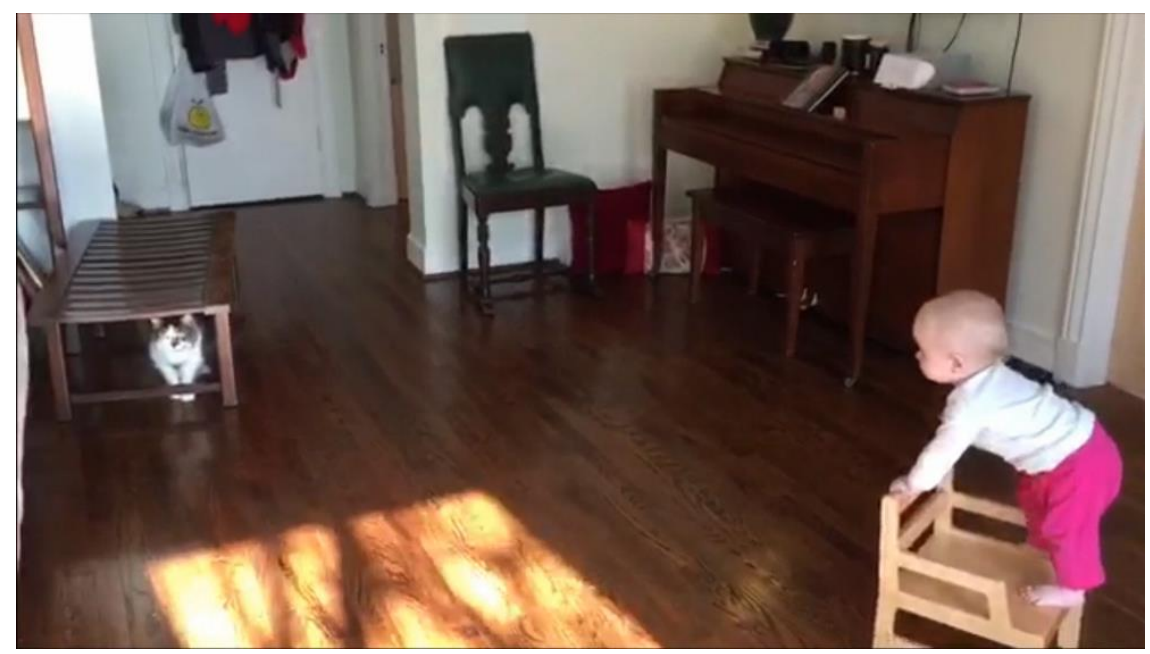

FEATURE Deborah Silvis' article comprises six videos which can be viewed here.

\section{Introduction}

As cameras become smaller and more light weight - as well as more affordable and accessible - they are now commonly found in all kinds of spaces and settings where children learn. There are many important questions now being asked about video technologies' ethical, epistemological, theoretical, and technical ramifications in research arrangements (Bates, 2015; Derry et al., 2010; MacLure, Holmes, MacRae \& Jones, 2010; Pink, 2015; Taylor, Silvis \& Bell, 2018; Vossoughi \& Escude, 2016; Umphress \& Sherin, 2015). Educational researchers have paid less attention to the aesthetic dimensions of video based research. That is, what goes into making 'good' video? Furthermore, how does the desire to produce video with high production values contribute to - or complicate - our ability to see and make sense of video recordings of learning. In other words, what does it mean to create well-produced video of learning when part of what we are producing is a rendering of other people's knowledge?

On the one hand, it is important to create high resolution video with crisp, clear sound and with high stability (Erickson, 2011). Well-produced video is easier to analyze and it facilitates dissemination of research that is based on video data. On the other hand, standards of video production entail theoryladen assumptions about just what it is we think video is meant to portray about an event once we leave the research setting (Hall, 2000). Well produced video can leave one with the mistaken impression that video provides 
unmediated access to the experiences of learners. This epistemological assumption intensifies when the video is recorded from the perspectives of learners themselves (e.g. Umphress \& Sherin, 2015). As first person perspective video and other forms of participant-created video recording de-center the researcher as the video producer, this then makes way for other producers of knowledge (Pink, 2015). It also produces novel sociotechnical or digital material arrangements (Pink, Lingard \& Harley, 2016). And for young children, this can then generate new subject positions, where they are produced as knowledgeable people.

For studying children as young as infants, epistemological questions ramify. While providing cameras to young children participating in research is now becoming common, there is a dearth of video recordings produced by or with children who do not yet walk or talk. There are likely a number of reasons for this. First, camera equipment is not conducive to early motor ability, grasping being a sort of prerequisite skill for conducting video recording. Even small body mounted action cameras present challenges (where to mount it; how to keep the camera lens unobstructed when infants roll around or crawl, etc.). This then introduces a second obstacle hindering infant video recording: the ethics of recording (with) infants and important issues regarding informed consent (Rutanen, Amorim, Marwick \& White, 2018). Third, while infantproduced footage is compelling to watch, its aesthetic qualities often prove problematic for analytic purposes. If first person perspective video offers researchers a vantage point on understanding the sense-making of participants who walk around and talk about their experiences, this technological affordance fails to transfer to analysis of infants' knowledge.

This article discusses a relationship between emerging methods for video recording young children's learning and the nature of the knowledge that is produced by such new forms of video. The discussion involves several strands as ways of examining this relationship. First, I outline benefits of video within the epistemological territory that infants inhabit and I relate this to decolonial perspectives. Then, I describe an ethnographic project designed to collect video of learning from an infant's perspective using a number of video methods. Next I reflect on how an analytic lens on the types of data collected proved inadequate for conveying infants' particular ways of knowing; this led to the development of a method of montage filmmaking mobilizing the blurry, low quality infant-collected footage. Finally, I discuss how tensions between these two moments of research - the collection/analysis phase and film/composition phase - opened up possibilities for co-producing knowledge with infants. I then gesture towards possibilities of methods attuned to 
aesthetic dimensions of video for participants whose knowledge we would like to learn to treat differently.

\section{$2 \quad$ Situated Knowledges and Epistemic Heterogeneity}

One thing video is particularly good at capturing is something often underplayed in qualitative studies that rely on methods like interviewing: the situation or context of research. Goffman's (1964) concerns about the "neglected situation" are seemingly resolved by video recordings. Video recordings can convey how activities observed during fieldwork were based in dynamic, concrete contexts and were interactionally achieved. Situated or perspectival accounts of learning are epistemological tools that help social scientists understand how knowledge varies by the socially located knower (Bang, 2015; Haraway, 1988; Harding, 2004; Lave \& Wenger, 1991). And yet, even first person perspective video still leaves unanswered important questions about "learning as a member's phenomenon" (Stevens, 2010). How do we use video to understand what learning was like for the person undergoing it in any given situation? Understanding situated knowledge as someone's particular point of view means asking these sorts of questions, and video recording methods only offer a partial response (Pink, 2015).

In contemporary digital and video-based research, the situatedness of everyday life has informed perspectives on contexts and spaces that emerge from the advent of ubiquitous digital technologies. It is now no longer sufficient to explain human activity as situated in 'a' place, when so much of what constitutes our environment and experiences is distributed across digital and physical spaces. Digital environments are both the grounds for much of our daily activity and the means of achieving it. That is, learning is both situated in and saturated by the digital with important implications for how we deal with digital video recordings in and of these spaces (Pink \& LederMackley, 2013. These "new spaces of learning" (Leander, Taylor \& Phillips, 2010) broaden the locations of learning and open up epistemic possibilities, expanding what counts as knowledge worthy of the name.

Epistemic heterogeneity is an organizing idea for decolonizing research (e.g. Barajas-Lopez \& Bang, 2018). The current article does not claim to be doing decolonizing research, however it is aligned with anti-colonial perspectives on knowledge politics in at least three ways. First, decolonizing methodologies require working in solidarity with one's own community to understand the world through particular onto-epistemic perspectives (Smith, 2012); I practiced a locally participatory politics of knowledge in the project I 
describe in this article. Second, my project is profoundly indebted to scholarship that aims to open up the possible perspectives from which people can speak and that seeks to amplify voices that are usually silenced or bodies that are typically shadowed in knowledge projects (e.g. Spivak, 1995).

At the same time, it is crucial to recognize colonialism's complicity with video production, notably through anthropology's history of producing ethnographic films and documentaries. Video has often served as a tool for exploiting the knowledge of Indigenous people or for making visible that which actually ought to remain invisible to the white settler gaze. Postcolonial filmmaker and philosopher Minh-ha (1991) questioned anthropologists who desired "to teach people with a culture different from ours to make motion pictures depicting their culture and themselves as they saw fit" (p. 72). In my project of making a film with an infant, I attempted to trouble what Minh-ha (2013) more recently critiqued: a "factitious claim to objectivity and the pursuit of naturalism in the development of a media technology that promotes the illusion of increasingly unmediated access to reality" (p. 150). Insofar as first person perspective video advances original colonialist visions of giving voice to the voiceless, I am sensitive to such "settler moves to innocence" (Tuck \& Yang, 2012, p. 1).

Given such critiques, and following Tuck \& Yang (2012), I believe that decolonization is not a metaphor. As they incisively wrote, "when metaphor invades decolonization, it kills the very possibility of decolonization; it recenters whiteness, it resettles theory, it extends innocence to the settler, it entertains a settler future" (p. 3). In contexts of ongoing settler colonialism (such as the United States, where this study is set), we must consider how these same contexts are today saturated by and situated in digital material environments (Pink \& Leder-Mackley, 2013). It is in this spirit of entangled political and onto-epistemic contexts, that I discuss a notion of unsettling video in the remainder of this article. This notion merely gestures to what is yet unsettled about learning but stops short of claiming to be doing important work of decolonization that would literally unsettle territories. While such work is happening in other locations in early childhood research (see elsewhere in this special issue), my particular project was concerned with infants' unique ways of knowing, as an important form of epistemic heterogeneity we might learn to see and hear better. 
But how to listen to those who do not have a voice, because they literally do not possess verbal language? This paper builds on several decades of work repositioning young children as participants in research (Christensen \& James, 2000). It also pushes on these same foundations insofar as textual accounts tend to reinscribe the dominant verbal modality as a means of listening to children's perspectives. Despite the fact that preverbal children's ways of knowing exemplify how knowledge is achieved through intersubjective, multi-modal, and embodied interactions, studies of early childhood experience are typically predicated on linguistic sense-making (Trevarthan \& Malloch, 2009). Furthermore, while studies of learning increasingly engage the moving body as a resource for meaning making (e.g. Taylor et al., 2018; Hall, Ma \& Nemirovsky, 2015; Marin \& Bang, 2018), infants' situated knowledge remains paradoxically at the margins of scholarly attention, with some notable exceptions (e.g. Elwick \& Sumsion, 2013; Johansson, 2011). While a thorough discussion of the relationship between notions of voice, perspective, knowledge, and interest, and standpoint are out of the scope of this article, the methods developed for this study offer one possible way of investigating this philosophically rich conceptual terrain.

Feminist standpoint theory has carved out space for multiple standpoints from which people develop and assert their knowledge from the margins (Harding, 2004; Wylie, 2012). "A standpoint is not simply an interested position (interpreted as bias) but is interested in the sense of being engaged" (Hartsock, 1983, p. 285). Standpoint theory has also influenced and been influenced by film theory. For example, the films of Minh-ha present a "view from below" (Picart, 2001, p.207), a viewpoint from which much of infant life is literally situated. Standpoint theories are concerned with multiple perspectives, but to have a standpoint is more than to be situated some place. It also implies that you have something to actively contribute to/from that place. There is an assumption that you might literally stand in that place to point something out, an ableist construction of epistemic authority with notable exclusions, such as infants. What is the nature of an infant's standpoint? How might we research infant "voice" when they articulate their particular ways of knowing outside of verbal language (Johansson, 2011)?

This is a second way that video is particularly well suited to understanding learning: it is a medium that captures the embodied and moving forms of meaning-making (MacDougall, 2006). By centering the infant body as a vital source of knowledge, video-based research can become attuned to how meaning is underdetermined by spoken language (Wallerstedt, Pramling, 
Samuelson, 2011). And when cameras are not only trained on learners, but now can be tethered to them, video technologies have the capacity to capture video from the standpoint of pre-verbal children. In contrast to third-person perspective video, which presents more distal and disparate viewpoints, firstperson perspective video (FPPV) collection is more immediate and integrated; it presents a perspective that coheres around the participant's vantage point (Umphress \& Sherin, 2015). Repositioning video cameras may serve as a means of repositioning research participants and redistributing agency within a larger research apparatus. At the same time, this move introduces new ethical, epistemological, and as I will argue, aesthetic dilemmas.

\section{Designing an Ethnographic Study of Infant Interest}

To address the lack of attention to infants as knowers, in 2014-2016 I conducted a digital ethnography of an infant and his mother interacting in their home environment (Pink, Horst, et al., 2016). I (and his mother, who is my sister) were particularly interested in his interests (in the sense that Hartsock defined interests in the earlier quote), how they developed over time, and how an infant's interests could be understood, given his preverbal status. Studying a family member in social science research is not uncommon, particularly in informal settings like homes (e.g. Kelly, 2015; Miller \& Sinanan, 2014). Of course, a limitation of conducting insider research is potential bias or lack of objectivity. The present article neither attempts to generalize findings nor to claim distance from activities of family life. Rather, I will argue that co-production is a vital form of knowledge production in which researchers and participants are both intimately involved and inherently coimplicated (Barad, 2007).

My data were primarily video based, and we used a number of different methods of video capture including camera phone video, FaceTime screen capture, GoPro video, and webcam video used in Skype (e.g. Kelly, 2015; O'Hara, Black \& Lipson, 2015; Umphress \& Sherin, 2015). In this paper I focus on the Skype video, a form that enabled us to co-produce data using two-way web enabled cameras on our laptops or smartphones (Miller \& Sinanan, 2014). I also touch on first person perspective video, which my nephew began to collect as our study progressed into his/its second year.

Doing research with infants is ethically fraught. One the one hand, incorporating infants in participatory research responds to an ethical imperative to consider ideas and knowledge from the margins. On the other, concerns about informed consent, vulnerability of subjects, and autonomy are

VIDEO JOURNAL OF EDUCATION AND PEDAGOGY 4 (2019) 1-23 
not easily reconciled for preverbal research subjects (Christenson \& James, 2010; Elwick, 2015). Furthermore, the risks of confidentiality and compromised data privacy are compounded by digital video production and dissemination and by the long life of video traces (Hall, 2000). These issues were the subjects of ongoing conversations with my sister, who herself produced many smartphone videos, which she shared with me (specifically for our research) and with our extended family online and through text messages. Parents and children hold a range of beliefs about their online presence (Livingstone, 2008; Livingstone, Stoilova, Nandagiri, 2018), with infants arguably being the most vulnerable. As research continues to include infants and increasingly involves media like video as data, ethical questions require ongoing discussion and deliberation.

Our decisions to utilize computer-mediated communication (CMC) technologies, action cameras, and smartphones as a means of doing research were initially based less on a desire to capture video from my nephew's perspective and were driven more by the exigencies of conducting research across locales. My sister lives in the middle of the US, while I lived on the west coast, so we developed data collection methods that supported virtual copresence and remote collaboration (e.g. Kelly, 2015). In year two of our study, we found that we needed to innovate based on a shared insight that this baby, now much more mobile, was becoming highly interested in the very technologies we were using to gather data and study his developing interests (i.e. cameras and screens).

Initially my nephew's interests centered around toys and activities that are stereotypical from a Western frame: mobiles; rattles; books; balls; blocks; boxes with shapes; puzzles; and stuffed animals. Then, around the age of eight months, when he learned to crawl, he sought out his mother's laptop whenever we were Skyping. His (and our) preoccupation with this technology sometimes led to frustrations and occasionally ended our meetings, my sister and I continuing the conversation by phone, where my virtual presence was less distracting. However, when he learned to walk and also became more dexterous, the cell phone itself became an object of interest. The entanglement of his mobility, technology, and methods presented a new set of questions that ultimately led us to explore new filmmaking methods, which I describe shortly.

We eventually made my sister's smartphone available for him to carry during Skype calls, enabling Guided Access features on her iPhone that blocked most of the buttons from being inadvertently pushed while engaged in a call. We also provided him with a small, inexpensive action camera for his own recordings. Smartphone video is reconfiguring research practices (Keep

VIDEO JOURNAL OF EDUCATION AND PEDAGOGY 4 (2019) $\quad$ 1-23 
\& Berry, 2013; van Doorn, 2013), however, there is not much known about how very young children might use handheld devices on their own to produce content or data. Smartphones are typically kept out of reach of young children, and pervasive concerns about screen time and fears about smartphone addictions tend to limit children's access to mobile devices. However, given changing practices in participatory research (e.g. Elwick, 2015; Sumsion, Bradley, Stratigos \& Elwick, 2014; White, 2016), it is worth exploring how very young children might record video from cameras embedded in smartphones, in addition to wearing or carrying action cameras. The methods we developed contribute to what has already been considered regarding infants' participation in video-based research and extend it by advancing the use of ubiquitous mobile technology like smartphones.

Although the video records we created together were not of the highest standards of video quality, I conducted video analysis of approximately two hundred hours of data, taking movement, mobility, the body, and relations with people and the more-than-human ecology of home as analytic foci. Using a constant comparative method (Charmaz, 2006) and interaction analysis (Jordan \& Henderson, 1995), I developed a theoretical framework for infant interest development based on infant mobility and interest in mobile technology. Yet, there was something deeply dissatisfying about the written form for conveying what had taken place in this digital ethnography and the particular, preverbal perspectives of my participant. I had somehow lost what had mattered during events (the material and embodied experience) in the quest for meaning making, which is traditionally the coin of the realm in qualitative research. Through my analytic treatment of the video data - as data - I had reinscribed the relentless rendering of the visual and mobile into the verbal and static.

MacLure (2014) noted that "coding recodes that which is already coded by language, culture, ideology and the symbolic order" (p. 170). She goes on to explain how coding arrests "the processual indeterminacy of movement and matter so that meaning, structure and order may transpire." Yet, it was precisely the processual indeterminacy of infants' relations with the world that I believed was important for understanding their ways of knowing. I began to suspect that my analytic approach had something to do with what I felt I had overlooked. This skepticism was born less of doubts about my methodological rigor or sophistication (although as a novice researcher at the time, this was surely part of it). Nor did it necessarily implicate some deficit in my nephew's knowledge (i.e. "lacking" language) as a source of epistemological indeterminacy. The problem, as I came to see it, was that while infants do not assert propositions in narrative prose, I had done so. What

VIDEO JOURNAL OF EDUCATION AND PEDAGOGY 4 (2019) $\quad$ 1-23 
the "data" seemed to demand was not analysis that terminated in statements and claims about meaning but a non-propositional means of recreating a moving experience that mattered from an infant's perspective.

After wrapping up empirical analysis, I returned to the video corpus recommitted to considering an infant's interests through a new lens - not the camera lens, or the analytic lens, but the aesthetic frame that took movement and the body as vital ways of knowing (e.g. Wallerstedt, Pramling \& Samuelsson, 2011). Even ethnographic approaches that understand data as created and constructed by ethnographers still subject data to the analytic gaze. This is the lens I had placed on the video during formal analysis, which reflected the analyst's will to know. On the other hand, montage film has been an alternative way that ethnographers have used for envisioning human experience, a form of ethnographic expression that imagines how experiences are emergent and not "given," as in formal readings of data (Rogers, 2015).

Typically, at this point in empirical articles, I would take the reader inside my analytic process, describing how I conducted interaction analysis, or explaining how grounded theory emerged from rounds of open coding while iteratively re-viewing the data corpus. Taking readers inside the development of an aesthetic medium like film, as a research method, requires a sort of reframing of the methodological process itself (Leavy, 20o9). During filmmaking, I was no longer relying on the data corpus to make sense of interactions and events. Nor was the film a form of data representation, like a moving version of still images that we include as evidence in empirical vignettes. Instead, the making of a film - the interplay of the video, its subject matter, and musical accompaniment - re-materialized the vitality of the original experiences captured in the video.

Whereas MacLure (2014) had expressed anxiety about the ways in which coding elided the "processual indeterminacy" of lived experience, regarding the same video footage as film created a space less constrained by the politics of interpretation, less reliant on words to convey voice. Minh-ha (2013) suggested how "as part of the processual filmic fabric that unfolds in front of the viewer, words question words, sounds echo sounds, internal and external voices mingle, while inquiries about the way these are being consumed are heard aloud" (p. 15o). The use of montage film is not a new idea in social science research (e.g. Liosi, 2018; MacLure et al., 2010). What is new is the use 
of smartphone video to explore how meaning-making, methodology, and aesthetics are reconfigured by infants as co-producers of film.

In creating the film, I centered the aesthetic of movement and music as organizing modes for reconceptualizing infants' embodied relations with the world. Drawing on the vitality of movement inherent in infant experience, I resisted an individualistic conception of inter-subjectivity, or the arbitrary separation of one person/object from another (Barad, 2007; Stern, 2010). I took interactions and events as configured through "communicative musicality" (Trevarthan \& Malloch, 2009), a way of being and knowing achieved by moving around the world together with other people and things. Communicative musicality reflects how the material and social environment is dynamically choreographed and is co-constitutive with an infant's mental life. Whereas, it had been challenging to address the sensuous, affective, and corporeal aspects of infant experience in standard narrative prose, the filmic medium made space for movement and the body to become visible and express vitality and intensity (Manning \& Massumi, 2014; Vannini, 2015). This body was not or not only the human (i.e baby's) body that was captured in and capturing - the film, but the entire assemblage of human and more-thanhuman actors, sounds, modes, and affects that co-produced events.

Focusing on these aspects, I selected clips from the video corpus that reflected key moments when vitality and intensity coursed through the footage. For example, one episode recorded by my sister on her smartphone featured my nephew around the age of eight months playing with the family cat, while she leapt and slid around the living room chasing a small orange whiffle ball (Clip A). Other clips involved his interactions with household furniture or objects that he banged on and pushed around while he engaged in what we called "heavy work," using maximum effort to move or carry things (Clip B). I used density of objects in the material ecology to figure intensity of affect and dynamic assemblage. For example, one of his primary ways of being interested in objects was a pattern we called "all the things," where he would enmesh himself (or his camera) within an elaborate, eclectic assortment of objects (balls, bottles, bowls, blocks, baskets, and other household items and toys) (Clip C). These types of events embodied a deep enjoyment of being in relation with the world and incorporated the vitality of affect so indicative of infant life (Stern, 2010). 


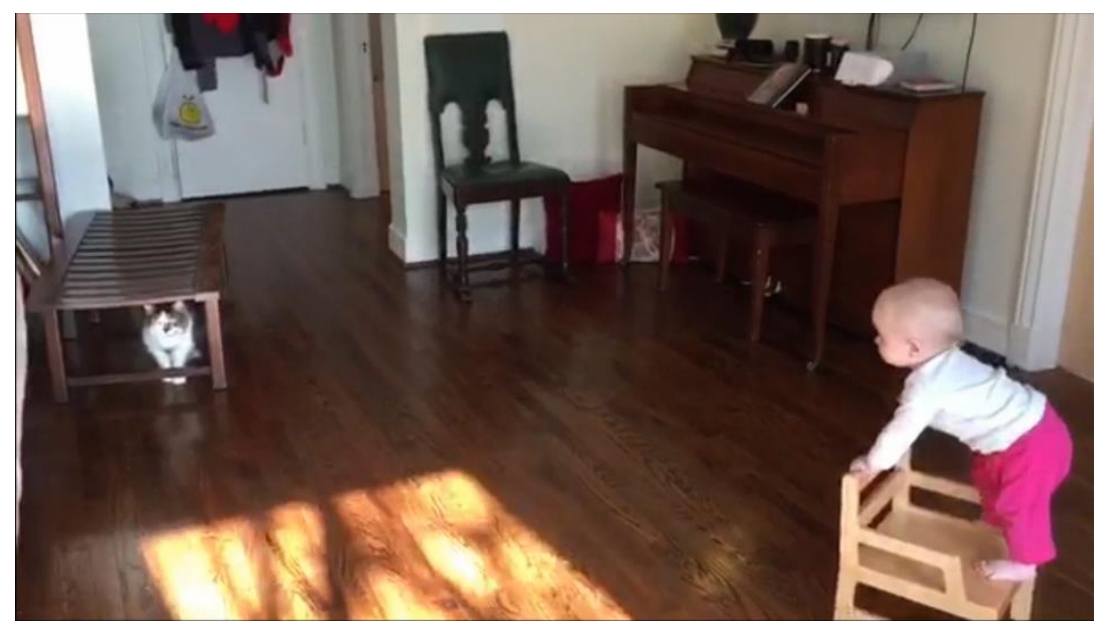

VIDEO 1 Film montage clip A: Cat. (See here.)

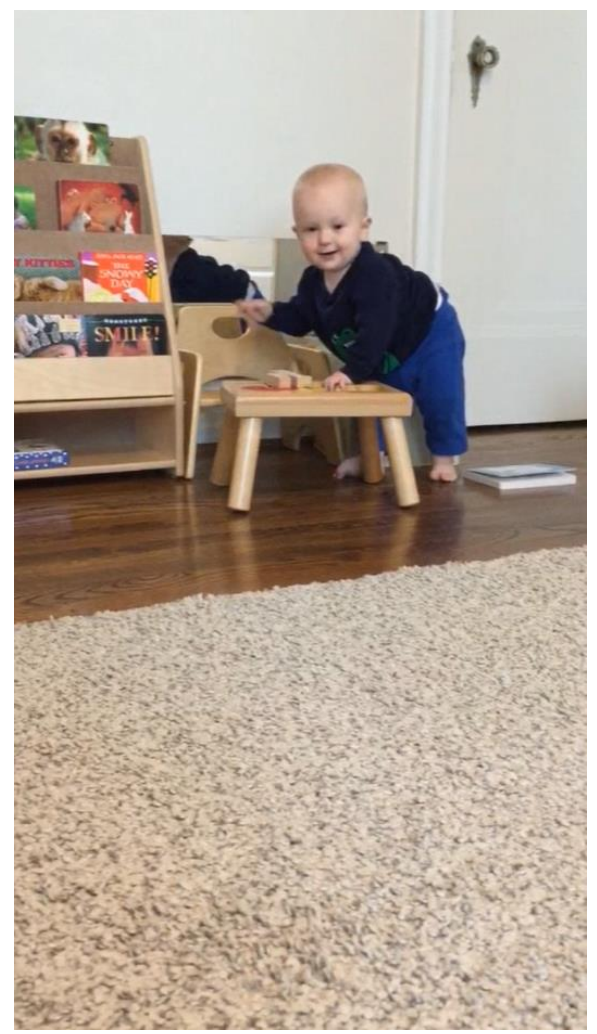

VIDEO 2 Film montage clip B: Pushing. (See here.)

VIDEO JOURNAL OF EDUCATION AND PEDAGOGY 4 (2O19) $\quad$ 1-23 


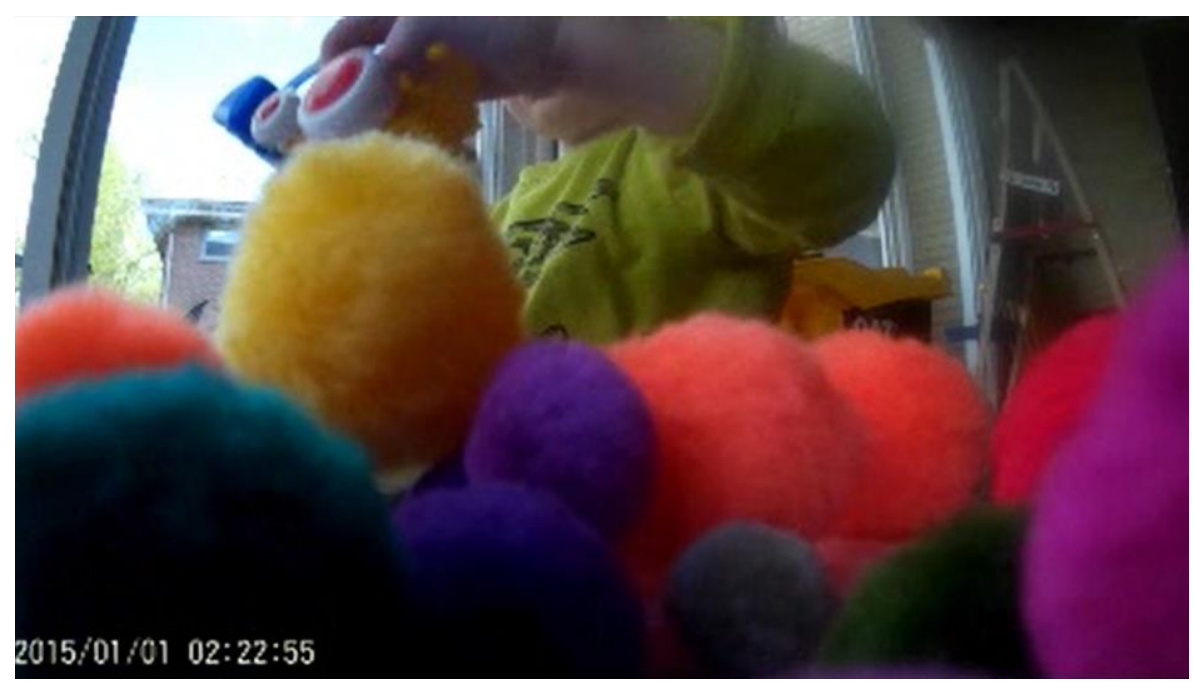

VIDEO $_{3}$ Film montage clip C: Balls. (See here.)

Throughout the process of culling clips like these from the larger corpus, I held in tension the relationship between video data and film footage. As I have mentioned, some of the video itself was not of great quality. Screen recordings of mobile Skype sessions had rendered video that was pixelated and grainy (Clip D). Broadband and processing speeds across our media ecology laminated technical complexity onto the footage, therefore compromising clips. The video collected by my nephew in the second year of the study was similarly blurry, jumpy, and stuttering (Clip E). FPPV like this is defined by onthe-move recording of people who may be walking or running, jumping, crouching, turning, and even cartwheeling (Taylor et al., 2018; Umphress \& Sherin, 2015). However, instead of a weakness, I took the quality of the video as a resource for developing the filmic thematic of dynamic motion and musicality. As embodied expressions of how research and knowledge production had transpired, the blurry footage reflected what it was like (for an infant) to shoot video and informed my approach to storyboarding scenes and editing clips. 


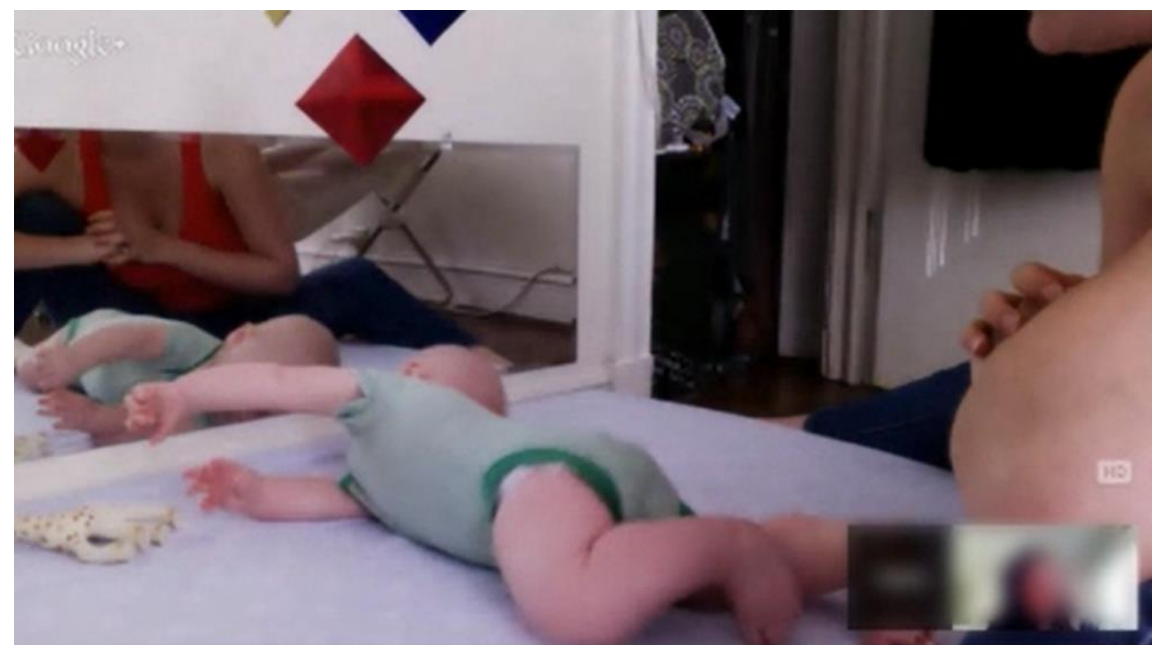

VIDEO 4 Film montage clip D: Grainy. (See here.)

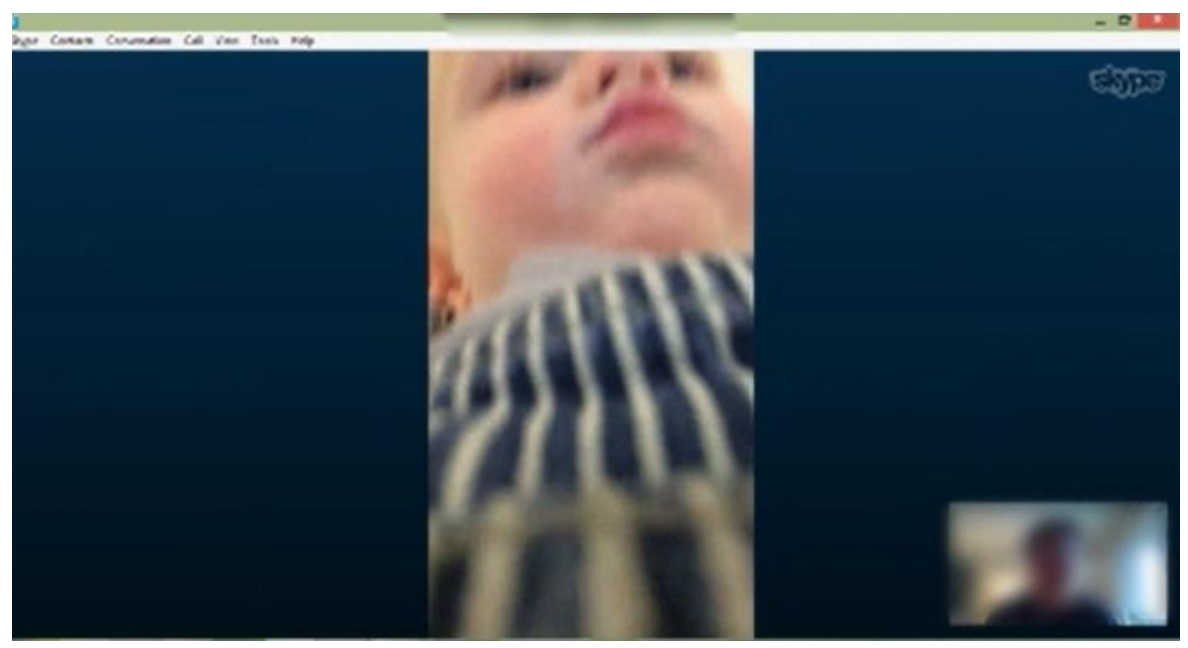

VIDEO $_{5}$ Film montage clip E: Blurry. (See here.)

I had initially thought to produce a silent film, muting the video's audio, to center the vital movements of the body. Vertov's (1929) famous film montage Man with a Movie Camera (Birdsall, 2015; Keep \& Berry, 2013) was my preliminary model, and I imagined a soundless rendition of key moments in our research as an "authentic" way of conveying infant knowledge. And yet, there is nothing silent about infants! Therefore, I decided to incorporate 
diegetic sounds (Gallagher, 2015) into the film. Breathing, vocalizations, and the constant noises babies make interacting with their environments (e.g. banging, pushing, scooting, sliding, tapping, scratching things) became important material for the film's soundtrack (Clip F).

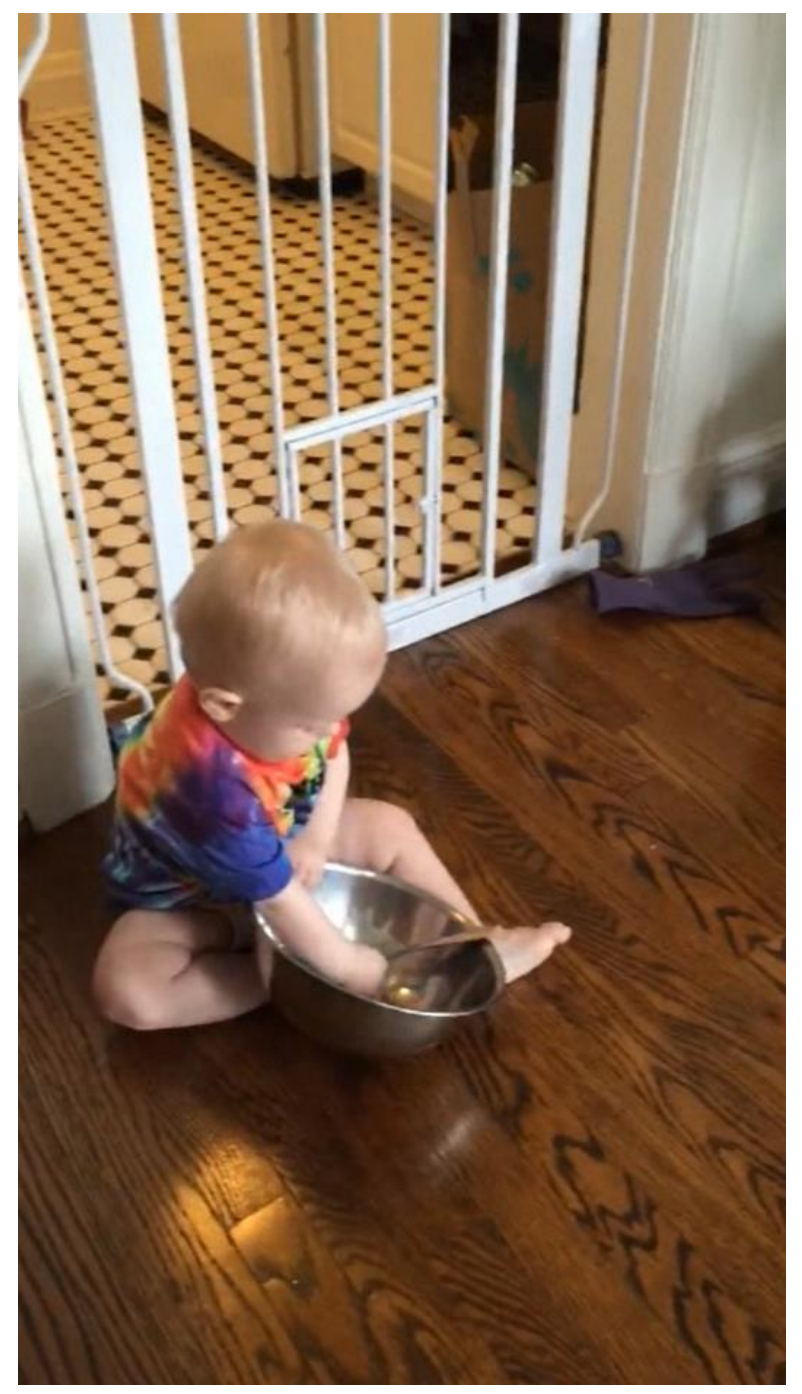

VIDEO 6 Film montage clip F: Noise. (see here.)

Experimenting with sound-mixing, I studied the use of sound in documentary films like Begg \& Hertzog's (2005) Grizzly Man and Chabat \& Balmès (2010) Babies, environmental tone poems like Reggio's (1982) Koyaanisqatsi: Life Out 
of Balance and sonic ethnographies like Castaing-Taylor's (2012) Leviathan. Arranging the film's soundtrack became a means of reanimating the dynamic, multi-sensory experiences we had undergone during initial video recording.

Background music was a critical mediational layer laminating sonic textures, movements, and intensities onto corporeal images, a means of literally expressing communicative musicality. I integrated the diegetic sounds with a musical score, editing footage to play in sync with the soundtrack. Music and the body, as modes of conveying meaning, converged at this moment of the filmmaking process. As Minh-ha (2013) put it "every sound, every noise can be made musical, especially when one works intensely with rhythm, resonance, and vibration" (p. 156). Thinking music, the body, intensity, and vitality together made it possible for me to arrange the movements in the video clips and accompanying diegetic sounds with a soundtrack. ${ }^{1}$ I treated the video editing process as a sort of choreographic practice. I titled the film Composing Commotion to reflect the musical contours of creating it and the collaborative, dynamic bodies that had co-produced the footage comprising it.

Today, there is so much we can do with video and sound recording technologies and with editing software in post-production that advances capabilities for research beyond analysis and coding. Nonetheless, in reflecting on co-producing video data and montage film with an infant, I have not meant to suggest that I have devised a new method. Ethnographic methods have long involved experimental documentary films (Kara \& Thain, 2015), and montage films have been incorporated in studies of learning (Liosi, 2018). Nor do I believe that my method of co-producing film should be taken as a form of arts-based methodology (Leavy, 2009); it was not for the purpose of creating a new form of representation that my method proved useful, although I did seek to distance my filmic approach from propositional prose. I also recognize a tradition of research designed to understand learning from members' perspectives (Stevens, 2010), which my method should not be taken as replacing. And I certainly do not claim that my film was an artistic masterpiece or a technical triumph (it is neither). What I believe this method offered was a means for rethinking the value of aesthetics and affect in coproducing knowledge, an issue I turn to next.

\footnotetext{
${ }^{1}$ I followed US government Guidelines for Fair Use of music and multimedia materials in the creation of the film for educational purposes. Unfortunately, I do not have copyright permission for the use of the music in publication.
} 


\section{Conclusion: Aesthetic Approaches Unsettle "production values"}

I originally began my study of infant interest asking a methodological question about how to mobilize video recording to understand infants' standpoints within the situated context of our particular research arrangement. Where empirical analysis of video using propositional language and the trained analytic gaze had flattened these experiences, the grammar of vitality - of living movement not contained in but moving through the body - found an outlet in video montage (MacDougall, 2006; Stern, 2010; Vannini, 2015). While making a montage film capitalized on an "authentic" aesthetic of blurry video recordings and the affects co-produced in and through them, such video troubles social science's established values governing empirical practices. Blurry footage is unsettling to watch and it unsettles objective criteria for understanding what other people know and can do. Minh-ha (1991) put it this way, "imperfect cinema is subversive... not because 'the larger the grain, the better the politics'; or because a shaky, blurry, badly framed shot is truer, more sincere, and authentic than a beautiful, technically masterful shot... [but because] the values that keep the dominant set of criteria in power are simply ineffective in a framework where one no longer abides by them" [emphasis added] (p. 71).

I think this signals an important tension between aesthetic values and epistemic values, a relationship between how (good) video and knowledge are produced. If an older ideal of video recording in research was that we should produce film of the highest quality that would assure objective analysis of the video corpus, then the advent of FPPV disrupts the epistemic ideal of objectivity (Daston \& Galison, 2007; Pink, 2015). This then co-produces new subject positions, new standpoints, from which knowledge becomes visible. Montage filmmaking was an authentic, aesthetic means of treating the coproduction of video and of infant's knowledge.

And yet, the promise of "authenticity" is as misleading in art as it is as a criterion of good science (Picart, 2001). The aesthetic will to represent natural, unfettered experience (inherent to the art of filmmaking) is just as fraught as the epistemological will to produce natural, objective truth (inherent to the science of coding). Film is not a way out of relations of power, it is a means of reflecting on the on-going process of an "exploitive system of visibility" (Minha, 1991), in which both analyst and filmmaker play a role. In treating embodied experience as a leading motif in the film, I remain cognizant of the on-going risk of objectifying and romanticizing the nature of infancy, a problem well known to critical scholars of young children's knowledge and agency (Canella \& Viruru, 2004; Taylor, 2013). In light of these considerations,

VIDEO JOURNAL OF EDUCATION AND PEDAGOGY 4 (2O19) 1-23 
what possibilities lie in treatments of research participants and video data through an aesthetic lens?

What co-producing a film with an infant did do was to reanimate some of the sensibilities and affects of being an infant and of being with an infant who is coming into relation with the world. Vitality pulses through human and more-than-human configurations, and learning is always situated in such dynamic ecologies of knowledge. Musicality, which figured as background music in the film is an important mode through which humans organize learning environments and also a vital means of making sense of what matters for learning in any situation (Phillips \& Lund, 2019). Similarly, intensities of movement are ways of knowing and relating to spaces, places, people, and things through assembled bodies. These phenomenological aspects of learning and everyday life are not readily accessed through the grammar of qualitative analysis or representational approaches. They become partially perceptible through an aesthetic, not an analytic lens. Methods like montage filmmaking, then, are a means of "evoking, not capturing" (Vannini, 2015, p. 231) what people know and can do.

Co-producing montage films introduces a number of questions, as opposed to serving as a template for other researchers who study infants' knowledge or other filmmakers interested in featuring young children in their films. One question I already suggested is: how does the idea of co-production unsettle taken for granted assumptions about who produces knowledge and reframe knowledge as relational? Another series of questions has to do with the lenses or frameworks to which we subject our video recordings (of learning or anything else): in what ways is this data a reflection of what took place? What is hidden from view through a framing of video as data? And as a response to this last question: What possibilities are opened up through a reframing of video data as artistic material? What then are we able to see about learning that was imperceptible to the analytic gaze? Like an infant learning to move around and relate to the world, unsettling knowledge hierarchies is a slow process. Perhaps attending to aesthetic values in our video-based methods can be a tool for both.

\section{Acknowledgements}

Many thanks to my beloved family for making this research possible and to Katie Headrick Taylor and Sasha Welland for support with video analysis and film-making, respectively.

VIDEO JOURNAL OF EDUCATION AND PEDAGOGY 4 (2O19) $\quad$ 1-23 


\section{References}

Bang, M. (2015). Culture, learning, and development and the natural world: The influences of situative perspectives. Educational Psychologist, 50:3, 220-233.

Bang, M. \& Marin, A. (2018). "Look it, this is how you know:" Family forest walks as a context for knowledge-building about the natural world. Cognition \& Instruction, $36: 2,89-118$.

Barad, K. (2007). Meeting the universe halfway: Quantum physics and the entanglement of matter and meaning. Durham, NC: Duke University Press.

Barajas-Lopez, F. \& Bang, M. (2018). Indigenous making and sharing: Claywork in an Indigenous STEAM program. Equity \& Excellence in Education, 51(1), 7-20.

Bates, C. (2015). Intimate encounters: Making video diaries about embodied everyday life. In C. Bates (Ed.), Video Methods: Social Science in Motion. London: Routledge.

Beggs, K. \& Hertzog, V. (2005). Grizzly Man. USA: Lions Gate Films.

Birdsall, C. (2015). Resounding city films: Vertov, Ruttmann and early experiments with documentary sound aesthetics. In H. Rogers, (Ed.), Music and Sound in Documentary Film. NY: Routledge.

Canella, G.S. \& Viruru, R. (2004). Childhood and postcolonization: Power, education, and contemporary practice. NY: RoutledgeFarmer.

Castaing-Taylor, L. (2012). Leviathan. USA: Cinema Guild.

Chabat, A. \& Balmes, T. (2010). Babies. France: StudioCanal.

Charmaz, K. (2006). Constructing grounded theory: A practical guide through qualitative analysis. Thousand Oaks, CA: SAGE.

Christensen, P. \& James, A. (Eds). (2000). Research with children: Perspectives and practices. New York: Routledge.

Daston, L. \& Galison, P. (2007). Objectivity. NY: Zone Books.

Derry, S. J., Pea, R. D., Barron, B., Engle, R. A., Erickson, F., Goldman, R., ... \& Sherin, B. L. (2010). Conducting video research in the learning sciences: Guidance on selection, analysis, technology, and ethics. The Journal of the Learning Sciences, $19(1), 3-53$.

Elwick, S. (2015). 'Baby-cam' and researching with infants: Viewer, image and (not) knowing. Contemporary Issues in Early Childhood, 16(4), 322-338.

Elwick, S. \& Sumsion, J. (2013). Moving beyond utilitarian perspectives of infant participation in participatory research: Film-mediated research encounters. International Journal of Early Years Education, 21:4, 336-347.

Erickson, F. (2011). Uses of video in social research: A brief history. International Journal of Social Research Methodology, 14:3, 179-189.

Gallagher, M. (2015). Working with sound in video: Producing an experimental documentary about school spaces. In C. Bates (Ed.), Video Methods: Social Science in Motion. London: Routledge. 
Goffman, Erving. 1964. The neglected situation. American Anthropologist 66(6), part 2. $133^{-136 .}$

Hall, R. (2000). Video recording as theory. In D. Lesh \& A. Kelley (Eds.), Handbook of Research Design in Mathematics and Science Education, 647-664. Mawah, NJ: Lawrence Erlbaum.

Hall, R., Ma., J.Y., \& Nemirovsky, R. (2015). Rescaling bodies in/as representational instruments in GPS drawing. In V. Lee (Ed.) Learning Technologies and the Body: Integration and Implementation in Formal and Informal Learning Environments. New York: Routledge.

Haraway, D. (1988). 'Situated Knowledges': The science question in feminism and the privilege of partial perspective', Feminist Studies 3: 575-599.

Harding, S. (2004). Standpoint theory as a site of political, philosophic, and scientific debate: In S. Harding (Ed.), The Feminist Standpoint Theory Reader: Intellectual and Political Controversies. NY: Routledge.

Hartsock, N. (1983). The feminist standpoint: Developing the ground for a specifically feminist historical materialism. In M.B. Hintikka \& S. Harding (Eds.), Discovering Reality, pp. 283-310. NY: Kluwer Academic Publishers.

Johansson, E. (2011). Giving words to children's voices in research. In Johansson \& E.J. White (Eds.), Educational Research with Our Youngest: Voices of Infants and Toddlers. London: Springer.

Jordan, B. and Henderson, A. (1995). Interaction analysis: Foundations and practice. The Journal of the Learning Sciences 4(1), 39-103.

Kara, S. \& Thain, A. (2015). Sonic ethnographies: Leviathan and new materialisms in documentary. In H. Rogers, (Ed.), Music and Sound in Documentary Film. NY: Routledge.

Keep, D. \& Berry, M. (2013). Re-mediating Vertov: Man with a movie camera phone. Ubiquity: Journal of Pervasive Media, 2.

Kelly, C. (2015). 'Let's do some jumping together': Intergenerational participation in the use of remote technology to co-construct social relations over distance.Journal of Early Childhood Research, 13(1), 29-46.

Lave, J. \& Wenger, E. (1991). Situated learning: Legitimate peripheral participation. Cambridge, UK: Cambridge University Press.

Leander, K.M., Phillips, N.C., \& Taylor, K.H. (2010). The changing social spaces of learning: Mapping new mobilities. Review of Research in Education, 34(1), 329-394.

Leavy, P. (2009). Method meets art: Arts-based research practice. NY: Guilford Press.

Liosi, M. (2018). Activist videos: Montage as a creative tool for students reflections on their role as spectators. Video Journal of Education and Pedagogy, 3:11, https://doi.org/10.1186/s4099o-018-0o24-o. 
Livingstone, S. (2008). Taking risky opportunities in youthful content creation: Teenagers' use of social networking sites for intimacy, privacy, and self-expression. New Media \& Society, 10(3), 393-411.

Livingstone, S., Stoilova, M., Nandagiri, R. (2018). Children's data and privacy online: Growing up in a digital age. Evidence Review. LSE Media and Communications.

MacDougall, D. (2006). Film, ethnography, and the senses: The corporeal image. Princeton, NJ: Princeton University Press.

MacLure, M. (2014). Classification or wonder? Coding as an analytic practice in qualitative research. In R. Coleman \& J. Ringrose (Eds.), Deleuze and Research Methodologies. Edinburgh, UK: Edinburgh University Press.

MacLure, M., Holmes, R., MacRae, C. \& Jones, L. (2010). Animating classroom ethnography: Overcoming video fear. International Journal of Qualitative Studies in Education, 23:5, 543-556.

Manning, E. \& Massumi, B. (2014). Thought in the act: Passages in the ecology of experience. Minneapolis, Minnesota: University of Minnesota Press.

Miller, D. \& Sinanan, J. (2014). Webcam. Maldan, MA: Polity Press.

Minh-ha, T. (1991). When the moon waxes red: Representation, gender, and cultural politics. NY: Routledge.

Minh-ha, T. (2013). D-passage: The digital way. Durham, NC: Duke University Press.

O'Hara, K., Black, A. \& Lipson, M. (2015). Media spaces and mobile video telephony. In S. Harrison (Ed.), Media Space 20+ Years of Mediated Life. London: Springer.

Phillips, N. \& Lund, V. (2019). Sustaining affective resonance: Co-constructing care in a school-based digital design studio. British Journal of Educational Technology, $50(4), 153^{2-1543 . ~}$

Picart, C.J.S. (2001). Working at the limen: Repositioning authority in science and art. In M. Mayberry, B. Subramaniam \& L.H. Weasel (Eds.), Feminist Science Studies: A New Generation. NY: Routledge.

Pink, S. (2015). Going forward through the world: Thinking theoretically about first person perspective digital ethnography. Integrative Psychological \& Behavioral Science, 24(2).

Pink, S. \& Mackley, K.L. (2013). Saturated and situated: Expanding the meaning of media in the routines of everyday life. Media, Culture \& Society, 35 (6), 677-691.

Pink, S., Ardevol, E. \& Lanzeni, D. (2016). Digital materialities: Design and anthropology. London: Bloomsbury.

Pink, S., Horst, H. Postill, J., Hjorth, L., Lewis, T., Tacchi, J. (2016). Digital ethnography: Principles and practices. Los Angeles: SAGE.

Pink, S., Lingard, L. \& Harley, J. (2016). Digital pedagogy for safety: The construction site as a collaborative learning environment. Video Journal of Education and Pedagogy, 1:5. DOI 10.1186/s4099o-016-ooo7-y.

Reggio, G. (1982). Koyaanisqatsi: Life Out of Balance. USA: American Zoetrope.

VIDEO JOURNAL OF EDUCATION AND PEDAGOGY 4 (2O19) 1-23 
Rogers, H. (2015). Introduction: Music, sound, and the nonfiction aesthetic. In H. Rogers, (Ed.), Music and Sound in Documentary Film. NY: Routledge. Soto, L.D. \& Swadener, B.B. (Eds.). (2005). Power and voice in research with children. New York: Peter Lang.

Rutanen, N, Amorim, K.S., Marwick, H. \& White, J. (2018). Tensions and challenges concerning ethics on video research with young children - experiences from an international collaboration among seven countries. Video Journal of Education and Pedagogy, 3:7, doi.org/10.1186/s4099o-018-oo19-x.

Smith, L.T. (2012). Decolonizing methodologies: Research and Indigenous peoples, 2nd edition. London, Zed Books.

Spivak, G. (1995). Can the subaltern speak? In B. Ashcroft, G. Griffiths \& H. Tiffin (Eds.), The Post-Colonial Studies Reader. London: Routledge.

Stern, D. (2010). Forms of vitality: Exploring dynamic experience in psychology, the arts, psychotherapy, and development. NY: Oxford University Press.

Stevens, R. (2010). Learning as a members' phenomenon: Toward an ethnographically adequate science of learning. National Society for the Study of Education, 100:1, 8297 .

Sumsion, J., Bradley, B., Stratigos, T. \& Elwick, S. (2014). 'Baby Cam' and participatory research with infants: A case study of critical reflexivity. In M. Fleer \& A. Ridgway (Eds.), Visual Methodologies and Digital Tools for Researching with Young Children: Transforming Visuality. Springer.

Taylor, K.H., Silvis, D., Bell, A. (2018). Dis-placing place-making: How AfricanAmerican and immigrant youth realize their rights to the city. Learning, Media and Technology, 43:4, 451-468.

Taylor, A. (2013). Reconfiguring the natures of childhood. London: Routledge.

Trevarthan, C. \& Malloch, S. (2009). Musicality: Communicating the vitality and interests of life. In C. Trevarthan \& S. Malloch (Eds.), Communicative Musicality: Exploring the Basis of Human Companionship. Oxford University Press.

Tuck, E. \& Yang, K.W. (2012). Decolonization is not a metaphor. Decolonization: Indigeneity, Education \& Society, 1:1, pp. 1-40.

Umphress, J. \& Sherin, B. (2015). The body as viewfinder: Using wearable cameras in learning research. In V. Lee (Ed.) Learning Technologies and the Body: Integration and Implementation in Formal and Informal Learning Environments. New York: Routledge.

van Doorn, N. (2013). Assembling the affective field: How smartphone technology impacts ethnographic research practice. Qualitative Inquiry, 19(5).385-396.

Vannini, P. (2015). Video methods beyond representation: Experimenting with multimodal, sensuous, affective intensities in the 21st century. In C. Bates (Ed.), Video Methods: Social Science in Motion. London: Routledge.

Vertov, D. (1929). Man with a Movie Camera. Soviet Union: VUFKU. 
Vossoughi, S. \& Escude, M. (2016). What does the camera communicate? An inquiry into the politics and possibility of video research on learning. Anthropology \& Education Quarterly, 47:1, 42-58.

Wallerstedt, C., Pramling, N. \& Samuelsson, I.P. (2011). Embodied voices and voicing embodied knowing: Accessing and developing young children's aesthetic movement skills. In Johansson \& E.J. White (Eds.), Educational Research with Our Youngest: Voices of Infants and Toddlers. London: Springer.

White, E.J. (2016). More than meets the "I": A polyphonic approach to video as dialogic meaning-making. Video Journal of Education and Pedagogy, 1:6, 1-14.

Wylie, A. (2012) "Standpoint Matters: Feminist Philosophy of Science," Pacific Division Presidential Address, Proceedings and Addresses of the American Philosophical Association, 86.2: $47-76$. 